\title{
TRANSPARÊNCIA PÚBLICA E A ATUAÇÃO NORMATIVA DO CNJ *
}

\author{
Rosane Leal da Silva, Patrícia Adriani Hoch e Lucas Martins Righi
}

\section{RESUMO}

O DIREITO FUNDAMENTAL À INFORMAÇÃO, PREVISTO NO ARTIGO $5^{\circ}$, XIV, DA CF, RESULTA NOS DEVERES DE TRANSPARÊNCIA pública ativa e passiva da Administração Pública. Através DO MÉTOdo DEDUtivo DE ABORDAGEM, O PRESENTE ESTUdO ABORda A ATUAÇÃo do CONSElHo NaCIONAL dE JUSTIÇA (CNJ), NO ÂMBITO DE SUA COMPETÊNCIA NORMATIVA, A FIM DE EFETIVAR A TRANSPARÊNCIA NO PODER JUDICIÁRIO, A PARTIR DA UTILIZAÇÃo dAS TECNOLOGIAS dE INFORMAÇÃo E COMUNICAÇÃo, ESPECIALMENTE A INTERNET. AO FINAL, APÓS UTILIZAC̣ÃO DAS TÉCNICAS DE PESQUISA BIBLIOGRÁFICA E DOCUMENTAL ALIADAS AO MÉTODO DE PROCEDIMENTO COMPARATIVO, EMPREGADO PARA CONTRASTAR AS DISPOSIÇÕES TRAZIDAS PELAS RESOLUÇÕES DO CNJ E PELA LEI N. 12.527/11 (LAI), CONCLUIU-SE QUE A ATUAÇÃO DO CNJ, NO CONTEXTO DA SOCIEDADE INFORMACIONAL, É POSITIVA EM ALGUNS PONTOS, COMO PUBLICIDADE DAS INFORMAÇ̃̃ES DA EXECUÇÃO ORÇAMENTÁRIA, GESTÃO FINANCEIRA E DE RECURSOS HUMANOS, MAS INSUFICIENTE EM RELAC̣ÃO A OUTROS, NOTADAMENTE A TRANSPARÊNCIA PÚBLICA PASSIVA.

\section{PALAVRAS-CHAVE}

DIREITOS FUNDAMENTAIS; INTERNET; SOCIEDADE INFORMACIONAL; transparência; Conselho Nacional de Justiça.

\begin{abstract}
THE FUNDAMENTAL RIGHT TO INFORMATION REFERRED TO IN THE ARTICLE 5TH, XIV, OF THE FEDERAL CONSTITUTION, RESULTS IN THE DUTIES OF ACTIVE AND PASSIVE PUBLIC TRANSPARENCY OF PUBLIC ADMINISTRATION. THROUGH A DEDUCTIVE METHOD OF APPROACH, THIS STUDY APPROACH THE PERFORMANCE OF NATIONAL COUNCIL OF JUSTICE (CNJ) IN THE CONTEXT OF HIS NORMATIVE POWERS, IN ORDER TO CARRY OUT THE TRANSPARENCY IN THE JUDICIARY WITH THE USE OF INFORMATION TECHNOLOGY AND COMMUNICATION, SPECIALLY THE INTERNET. AT THE END, AFTER USING THE TECHNIQUES OF LITERATURE AND DOCUMENTS RESEARCH COMBINED TO THE COMPARATIVE PROCEDURE, EMPLOYED TO CONTRAST THE PROVISIONS BROUGHT BY CNJ RESOLUTIONS AND LAW NO. 12.527/11 - IAL, WE CONCLUDED THAT THE PERFORMANCE OF THE CNJ AT THE THEMATIC RESEARCHED, IN THE CONTEXT OF INFORMATIONAL SOCIETY, IS POSITIVE IN SOME PLACES, LIKE PUBLICITY OF BUDGET EXECUTION, FINANCIAL MANAGEMENT AND HUMAN RESOURCES INFORMATIONS, BUT INSUFFICIENT IN RELATION TO OTHERS, NOTABLY THE PASSIVE PUBLIC TRANSPARENCY.
\end{abstract}

\section{KEYWORDS}

FUNDAMENTAL RIGHTS; INTERNET; INFORMATION SOCIETY; transparency; National Council of Justice.

\section{INTRODUÇÃO}

A criação do Conselho Nacional de Justiça (CNJ), através da publicação da Emenda Constitucional n. 45/2004, foi precedida e sucedida de diversas celeumas relacionadas à sua natureza, constitucionalidade, legitimidade e efetividade. A razão para toda a atenção recebida em níveis doutrinários e jurisprudenciais não poderia ser outra 
senão os importantes poderes que esse órgão recebeu do constituinte derivado, respondendo pelo controle da atuação administrativa e financeira do Poder Judiciário.

Além de ter que executar a coordenação interna sobre os rumos do Judiciário, elaborando a política judiciária nacional e garantindo a autonomia e independência desse poder, o CNJ também deve primar pela prestação jurisdicional de qualidade e zelar pela atuação administrativa condizente com os princípios da legalidade, impessoalidade, moralidade, publicidade e eficiência, todos previstos no artigo 37 da Constituição Federal. Para que a atuação judicial seja coadunada com tais princípios constitucionais compete ao CNJ o cumprimento de importantes objetivos e atividades, com destaque para a promoção e coordenação de políticas visando à concretização da transparência pública. Esse dever ganhou novas nuances nos últimos anos em face da edição da Lei n. 12.527/2011, que regulamentou o direito de acesso à informação (LAI), cujo comando do artigo $8^{\circ}$ determinou o dever dos órgãos públicos de divulgar as informações de interesse público em seus sites e portais.

Esse novo cenário conduz ao seguinte questionamento: pode-se afirmar que o Conselho Nacional de Justiça incentiva a utilização das TIC's no âmbito do Poder Judiciário em favor de uma cultura de abertura e transparência? Em caso afirmativo, como tem sido sua atuação em face dessa nova realidade? Para responder a esse questionamento apresenta-se o presente artigo, cujo objetivo é divulgar os resultados parciais produzidos no âmbito do projeto de Pesquisa intitulado "O uso das tecnologias da informação e comunicação pelo Poder Judiciário brasileiro: os sites e portais como instrumentos para implementar a Lei n. 12.527/11", realizado com apoio do $\mathrm{CNPq}$.

Para a elaboração deste artigo utilizou-se o método de abordagem dedutivo, empregado para investigar como o Conselho Nacional de Justiça atua no âmbito de sua competência normativa visando à divulgação das informações relacionadas à atuação financeira e administrativa dos Tribunais. A essa metodologia agregaram-se as técnicas de pesquisa a) bibliográfica, objetivando estabelecer as principais categorias conceituais que compõem o ambiente temático; b) documental, com a análise sistemática e comparativa de todas as Resoluções publicadas pelo CNJ que determinam obrigações de transparência ativa e passiva aos órgãos do Poder Judiciário, a partir do uso das Tecnologias de Informação e Comunicação. As Resoluções investigadas, por sua vez, foram contrastadas com os dispositivos da Lei de Acesso à Informação (LAI), ocasião em que foi empregado o método de procedimento comparativo.

A partir dessa base metodológica, o artigo foi dividido em duas partes: o primeiro momento é mais conceitual, dedicado a discutir o dever de transparência, aproximando-o da atuação do Poder Judiciário, o que é feito com base principalmente nos referenciais teóricos de Manuel Castells e Pierre Lévy. A segunda parte do trabalho destina-se a discutir a atuação do Conselho Nacional de Justiça, com especial 
atenção para o poder normativo, fundamental para a expedição de atos regulamentares. Superada a fixação da base teórica essencial para a compreensão do tema, analisamse os resultados da pesquisa documental realizada, apresentando as Resoluções do CNJ que objetivam coordenar a política de promoção da transparência pública substanciada nas TIC's, especialmente a Internet. Esses referenciais obtidos são contrastados com o conteúdo da Lei de Acesso à Informação, o que é feito com o objetivo de responder se o CNJ está atuando positivamente com vistas a implementar a política de divulgação de informações referentes à atuação administrativa e financeira dos órgãos do Poder Judiciário.

\section{A EVOLUÇÃo do DEVER DE TRANSPARÊNCIA NA SOCIEDADE INFORMACIONAL}

Castells (1999, p. 26) utilizou o termo sociedade informacional para definir a nova vida em sociedade a partir da revolução tecnológica dos anos 1970, marcada pela utilização do meio eletrônico/digital e pelo fluxo rápido e contínuo de informações. Essa nova caracterização social decorre da utilização das Tecnologias da Informação e da Comunicação (TIC's), especialmente a Internet, que se destaca como a tecnologia informacional capaz de permitir grande circulação, disseminação, tratamento, recolhimento e armazenamento de dados e informações. Essa característica propicia e fomenta a comunicação, a interatividade e a aproximação de pessoas, o que ocorre tanto no setor privado quanto no âmbito público.

O uso da Internet contribuiu para a relativização do monopólio das informações até então concentradas nas mídias tradicionais, o que permitiu que os cidadãos tivessem acesso a fontes variadas e, por conseguinte, passassem a apresentar novas demandas ao Poder Público. Dentre os pleitos que ganharam força nos últimos anos destaca-se a reivindicação pela regulamentação do direito constitucional à informação pública dessa forma, alinhando o Brasil ao cenário internacional. ${ }^{1}$

Dentre os tratados internacionais sobre o tema, destacam-se no âmbito deste trabalho a Declaração de Atlanta, oriunda da Conferência Internacional em Atlanta, na Geórgia (EUA), realizada em 29 de fevereiro de 2008 (INTERNACIONAL, 2008, p. 1), e os princípios publicados no ano de 1999 pela Organização Não Governamental Artigo 19 (ARTIGO 19, 1999) cuja atuação em favor do acesso à informação pública se notabilizou em vários países. A escolha por esses documentos se deve ao fato de ambos apontarem as TIC's como aliadas no cumprimento do dever de transparência.

O primeiro documento parte da premissa de que "a informação é o oxigênio da democracia” e afirma que até "mesmo governos democráticos prefeririam conduzir a maior parte dos seus assuntos longe dos olhos do público”, o que faz com o objetivo de alertar para a necessidade de abertura das informações oficiais por parte dos Estados. Essa abertura seria obtida pela observância de nove princípios: 
1) a máxima divulgação da liberdade de informação; 2) a obrigação de que os órgãos públicos publiquem informações essenciais; 3) a promoção de um governo aberto por parte dos órgãos públicos; 4) a determinação clara e rigorosa de exceções, as quais devem ser sujeitas à efetiva prova do dano e ao interesse público; 5) as solicitações de informação devem ser processadas rapidamente e com imparcialidade, e uma revisão independente de quaisquer recusas deve estar à disposição das partes; 6) os custos excessivos não são causa de impedimento à solicitação de informações pelos cidadãos; 7) as reuniões dos órgãos públicos devem admitir a presença do público; 8) as leis que não obedecem à máxima divulgação devem ser alteradas ou revogadas e, por fim, 9) os indivíduos que denunciem irregularidades devem ser protegidos.

Nesse rol de princípios, merece ênfase o da máxima divulgação, segundo o qual "os organismos públicos têm obrigação de divulgar informação assim como todo o cidadão tem o direito correspondente de receber informação" (ARTIGO 19, 1999, p. 3). Desse modo, a regra seria a divulgação de informações, principalmente aquelas consideradas essenciais, sendo que a recusa na disponibilização da informação deveria ser legalmente excepcionada e acompanhada de justificativa pelo órgão público competente.

A Declaração de Atlanta, por sua vez, estabeleceu o acesso à informação como direito humano fundamental. Na oportunidade, 125 membros da comunidade global de acesso à informação, representando 40 países, entenderam que "o compromisso político com o direito de acesso à informação é necessário para a adoção, implantação e execução integral das leis e instrumentos sobre acesso à informação" (INTERNACIONAL, 2008, p. 2). Assim, tal Documento enumerou regras, princípios, premissas básicas e palavras-chave destinadas a efetivar o acesso à informação por meio da transparência, ao reconhecer que:

[...] o direito de acesso à informação é a base para a participação cidadã, boa governança, a eficiência na administração pública, a prestação de contas e esforços de combate à corrupção, a mídia e o jornalismo investigativo, o desenvolvimento humano, a inclusão social e a realização de outros direitos socioeconômicos e políticos e civis.

Em que pese a importância desse direito, foi enfatizado em Atlanta que, apesar dos avanços ocorridos no direito de acesso à informação, ainda existiam desafios, tais como a "ausência de legislação nacional, níveis bastante variados de implantação e resistência política contínua”, o que ainda pode ser verificado na atualidade e merece especial atenção por parte dos governos e da sociedade civil. A Declaração de Atlanta previu, ainda, nove conclusões importantes envolvendo o direito fundamental à informação: 
1. O direito fundamental de acesso à informação é inerente a todas as culturas e sistemas de governo;

2. A falta de acesso à informação afeta desproporcionalmente os pobres, as mulheres e outras comunidades vulneráveis e marginalizadas e, dessa forma, o direito deve ser garantido a todos os setores da sociedade;

3. O direito de acesso à informação é fundamental para a dignidade humana, equidade e paz com justiça;

4. A transparência é um instrumento necessário e poderoso para promover a segurança humana e do Estado;

5. As novas tecnologias apresentam grande potencial para facilitar o acesso à informação, embora os fatores limitantes ao acesso e às práticas de gerenciamento de dados tenham feito com que muitos não se beneficiem integralmente de seu potencial;

6. Promulgar uma lei abrangente é essencial, porém insuficiente para estabelecer e manter o direito de acesso à informação;

7. Também é fundamental construir um marco institucional adequado e desenvolver a capacidade da administração pública para gerenciar e prestar informação;

8. É essencial, ainda, promover a conscientização pública sobre o direito de acesso à informação, assegurar a capacidade de exercer o direito, inclusive mediante educação pública, e fomentar o apoio à transparência em todos os setores da sociedade;

9. Uma mídia livre e independente é um componente fundamental para o estabelecimento e exercício pleno do direito de acesso à informação.

A partir dessas conclusões, percebe-se que a referida Declaração evidenciou o potencial das novas tecnologias como promotoras do acesso à informação e reconheceu a transparência como um instrumento necessário para a melhoria da segurança humana e estatal, destacando, inclusive, a necessidade de que sejam asseguradas à população a conscientização e a capacidade para o exercício desse direito. Tais premissas, admitidas e ratificadas pela comunidade internacional, reforçam a importância da efetivação do direito humano fundamental à informação e à concretização da democracia tradicional e da ciberdemocracia, conforme será abordado mais adiante.

No âmbito interno dos Estados, a Declaração de Atlanta estabeleceu que esse direito deve ser observado pelos poderes Executivo, Legislativo e Judiciário em todos os níveis e áreas de atuação (INTERNACIONAL, 2008, p. 2-4). Por oportuno, é importante ressaltar que quatro anos antes da Declaração de Atlanta o Brasil já havia criado o Portal da Transparência, o qual representou marco inicial para a efetivação do direito fundamental de acesso à informação e o reconhecimento da importância da divulgação de dados de interesse público (BRASIL, 2004m). Todavia, o Legislativo e o Judiciário apresentaram uma reação tardia quanto a esses poderes-deveres, 
mantendo postura mais hermética em detrimento do princípio da publicidade, previsto no artigo 37 da Carta Constitucional.

Ocorre que todos os órgãos que cumprem funções públicas devem observar o dever de informação, independentemente do Poder ao qual se vinculem, pois conforme destacado por Miragem (2011, p. 308/309):

A noção de publicidade da ação administrativa, neste aspecto, resulta em um dever de transparência na exata medida em que estabelece como paradigma da ação administrativa sua exposição ao conhecimento público, para acesso de qualquer interessado, como condição, critério para sua legitimidade. O dever de transparência que resulta desta eficácia do princípio da publicidade abrange tanto os processos de decisão da Administração quanto informações públicas de um modo geral, refletindo a ação transparente do agente público e promovendo o uso público da razão nos assuntos de interesse geral da comunidade, sob o patrocínio ou com a participação do Estado.

Exatamente porque o processo de abertura e de maior transparência não ocorreu na mesma velocidade em todos os poderes, a Lei de Acesso à Informação (BRASIL, 2011-l) determinou que seus princípios se aplicassem aos órgãos públicos integrantes da administração direta dos Poderes Executivo, Legislativo (incluindo as Cortes de Contas) e Judiciário, além do Ministério Público - e, por fim, a aplicação se estendeu às autarquias, fundações públicas, empresas públicas, sociedades de economia mista e demais entidades controladas direta ou indiretamente pelos entes federados. Além disso, nos termos legais, a informação deve ser entendida em um sentido amplo, abrangendo, segundo o artigo $4^{\circ}$, I, “dados, processados ou não, que podem ser utilizados para produção e transmissão de conhecimento, contidos em qualquer meio, suporte ou formato" (BRASIL, 2011-l).

Com o escopo de assegurar o direito fundamental à informação ${ }^{2}$ e com base nos documentos internacionais já assinados pelo Brasil, a Lei n. 12.527/11 trouxe importantes diretrizes em seu artigo $3^{\circ}$ : I) observância da publicidade como preceito geral e do sigilo como exceção; II) divulgação de informações de interesse público, independentemente de solicitações; III) utilização de meios de comunicação viabilizados pela tecnologia da informação; IV) fomento ao desenvolvimento da cultura de transparência na administração pública $\mathrm{eV}$ ) desenvolvimento do controle social da administração pública (BRASIL, 2011-l).

A transparência deve ser entendida em sentido amplo, abrangendo a transparência ativa, que se efetiva na disponibilização de informações públicas de interesse geral ou coletivo de forma espontânea pelo Estado, e passiva, que ocorre quando o ente estatal responde às demandas formuladas pelos cidadãos através de meio físico ou digital (MARTINS, 2011, p. 2). Tais obrigações, apesar de distintas, possuem fundamental 
importância para a publicização de informações e para a consolidação da democracia no âmbito da sociedade informacional.

Diante disso, "seguindo uma tendência global, o Brasil tem investido em tecnologias da informação e comunicações (TIC's), como ferramentas de modernização da administração pública”, com destaque para a Internet, cuja rapidez, eficiência e possibilidade de oferta customizada permitem a disponibilização de serviços e aumentam a aproximação e a comunicação entre Estado e sociedade (BRASIL, 2011, p. 46a).

Como decorrência, a utilização das TIC's "aumentou a capacidade de a população fiscalizar o poder público e participar dos processos de tomada de decisão. Com isso, a informação se tornou ainda mais importante para os cidadãos [...], pelo respeito do direito de acesso à informação" (ARTIGO 19, 2009, p. 16). A essa vantagem soma-se o fato de a Internet abrir novos canais de comunicação e interação entre o Poder Público e a sociedade, revelando seu potencial para o fortalecimento da democracia.

Castells (2003, p. 128) ratifica a importância da Internet e seu potencial para inspirar novas posturas por parte da população e dos governantes:

Esperava-se que a Internet fosse um instrumento ideal para promover a democracia - e ainda se espera. Como dá fácil acesso à informação política, permite aos cidadãos ser quase tão bem-informados quanto seus líderes. Com boa vontade do governo, todos os registros públicos, bem como um amplo espectro de informação não sigilosa, poderia ser disponibilizado on-line. A interatividade torna possível aos cidadãos solicitar informações, expressar opiniões e pedir respostas pessoais a seus representantes. Em vez de o governo vigiar as pessoas, as pessoas poderiam estar vigiando o seu governo - o que é de fato um direito delas, já que teoricamente o povo é soberano.

Ocorre que a tecnologia não produzirá os efeitos desejados se não estiver acompanhada da mudança de postura por parte dos gestores públicos, que devem não só compreender a importância do acesso a dados de interesse público como reconhecer que o cidadão está legitimado a ir além do mero acesso à informação: tem o direito de exigir transparência, exercer o controle social, apresentar demandas e receber respostas. Com efeito, o uso das TIC's descortina novas funcionalidades e pode contribuir para o empoderamento político dos atores sociais, o que acabará por impor desafios aos gestores, gerando focos de tensão antes inexistentes.

Portanto, caso o avanço das TIC's venha acompanhado de novas posturas por parte dos agentes públicos, seu uso pode contribuir para enriquecer os processos de transparência e efetivar os valores democráticos, concretizando as potencialidades anunciadas por Lévy no final do século XX (1999, p. 186-196): 
A verdadeira democracia eletrônica consiste em encorajar, tanto quanto possível - graças às possibilidades de comunicação interativa e coletiva oferecidas pelo ciberespaço -, a expressão e a elaboração dos problemas da cidade pelos próprios cidadãos, a auto-organização das comunidades locais, a participação nas deliberações por parte dos grupos diretamente afetados pelas decisões, a transparência das políticas públicas e sua avaliação pelos cidadãos.

Para os mais otimistas, a Internet representa uma ágora virtual ao possibilitar maior participação do cidadão no debate e na tomada de decisões, bem como a revitalização da legitimidade democrática por meio de novos mecanismos de participação. Nesse sentido é o registro feito por Piana (2007, p. 148):

Desde esta perspectiva se ve a Internet como una ágora virtual. Se afirma que las TIC podrían crear nuevos canales facilitadores para una participación ciudadana responsable, revitalizando la legitimidad democrática ante los actuales niveles de desafección de la ciudadanía respecto a la cosa pública. Chats, Foros de discusión, Boletines de información, etc. han sido vistos como nuevos mecanismos participativos.

Com base nesse aporte teórico pode-se afirmar que a efetividade do direito ao acesso à informação pública, atualmente reconhecido como um direito humano fundamental, está diretamente relacionada à ciberdemocracia.

Ocorre que a democratização no tratamento das questões de interesse público não deve ficar adstrita ao âmbito do Poder Executivo e impõe que os demais poderes se tornem permeáveis ao controle social. Nesse sentido interessa analisar a atuação do Conselho Nacional de Justiça no desempenho da função de coordenar a política nacional de transparência pública no Poder Judiciário. Para tanto, o próximo tópico destina-se ao exame da competência normativa do Conselho Nacional de Justiça, o que será feito a partir da análise das Resoluções do CNJ e das iniciativas procedimentais adotadas com objetivo de efetivar o direito à informação e transparência no Poder Judiciário.

\section{Atuação do Conselho Nacional de Justiça como promotor DA TRANSPARÊNCIA NO PODER JUDICIÁRIO: UTOPIA OU REALIDADE?}

$\mathrm{Na}$ presente seção serão expostos os resultados da pesquisa, cujo objetivo principal foi analisar o exercício do poder normativo primário feito pelo Conselho Nacional de Justiça na promoção da transparência pública (ativa e passiva) desde sua criação. Para dar conta desse objetivo - e seguindo a metodologia adotada -, inicialmente 
foram abordados aspectos históricos da criação do CNJ, bem como suas principais características, culminando no estudo do poder normativo primário desse órgão, análise essencial para que se compreenda a condução da política administrativa interna do Poder Judiciário.

A essa abordagem preliminar segue-se a exposição das principais Resoluções do CNJ que abordam, ainda que parcialmente, o dever de transparência e o direito fundamental de acesso às informações públicas, e o contraste de seu teor com os dispositivos da Lei n. 12.529/11 - Lei de Acesso à Informação Pública.

\section{I O Conselho Nacional de Justiça:}

DA CONTROVÉRSIA À CONSOLIDAÇÃO CONSTITUCIONAL

Fruto da denominada "Reforma do Judiciário", instrumentalizada pela publicação da Emenda Constitucional n. 45/2004, o Conselho Nacional de Justiça é resultado de uma série de discussões sobre a criação de um órgão de controle externo sobre o Poder Judiciário. Ainda na Assembleia Nacional Constituinte já havia ocorrido intenso debate sobre a criação e regulamentação de um conselho destinado a controlar referido Poder (MACHADO, 2008, p. 61).

O tema nunca foi pacífico, principalmente entre os integrantes da magistratura, muito em razão da justificada independência decisional e institucional que referido Poder possui, a fim de exercer a Jurisdição como um meio de defesa de direitos e garantias individuais e sociais, ainda que em alguns momentos afrontando os demais Poderes - Executivo e Legislativo. Segundo alguns doutrinadores, "não se consegue conceituar um verdadeiro Estado Democrático de Direito sem a existência de um Poder Judiciário autônomo e independente, para que exerça sua função de guardião das leis" (MORAES, 2008, p. 512), de forma que "o primeiro indício de que o país está perdendo (claudicando) a democracia ocorre quando o Poder Judiciário está se enfraquecendo" (FERNANDES, 2011, p. 751).

Objetivando assegurar essa independência, a Constituição Federal de 1988 estabeleceu garantias institucionais e específicas para os integrantes da magistratura. As primeiras, que circundam a instituição como um todo, são manifestadas na seguinte tríade: autonomia funcional, administrativa e financeira do Poder Judiciário. A Autonomia administrativa funcional, entendida como capacidade de auto-organização, refere-se à capacidade de autogoverno dos Tribunais: elaboração dos regimentos internos, eleição dos órgãos diretivos, organização de secretarias, serviços auxiliares e dos juízos vinculados, provimento dos cargos de juiz de carreira da respectiva jurisdição e dos demais cargos necessários para a administração da justiça, proposta de criação de novas varas judiciárias, concessão de licenças, férias e outros afastamentos (FERNANDES, 2011, p. 751-752).

A autonomia administrativa financeira, por outro lado, restringe-se à possibilidade de os Tribunais formularem suas propostas orçamentárias para encaminharem aos 
demais Poderes responsáveis pela elaboração e aprovação da lei de diretrizes orçamentárias (FERNANDES, 2011, p. 752). Complementarmente, as garantias dos membros da magistratura consistem: a) na vitaliciedade que se traduz na prerrogativa de manutenção do cargo, que somente pode ser perdido por decisão judicial transitada em julgado, após dois anos de efetivo exercício e b) na inamovibilidade, que garante que as remoções ou promoções ocorram por vontade própria, c) ao que se soma a irredutibilidade de subsídios (MENDES, 2011, p. 970).

Natural, portanto, que a grande independência e autonomia do Poder Judiciário, asseguradas constitucionalmente pelas garantias anteriormente abordadas, sempre tenha sido o principal argumento dos que se opunham à criação de conselhos para o exercício de controle administrativo sobre o Poder Judiciário: havia o risco de que a constituição de órgão dessa natureza restringisse a independência dos Tribunais e magistrados, o que poderia afetar o exercício da Jurisdição, notadamente quando as lides envolvessem a Administração Pública e a discussão de políticas públicas (OLIVEIRA, 2010, p. 123).

Contudo, a despeito da inegável importância dessas garantias constitucionais, principalmente em um momento histórico marcado pela judicialização da política e pela inexistência de medidas suficientes para garantir a fiscalização e o controle dos tribunais por agente externo ou interno ao Poder Judiciário (RODRIGUES, 2008, p. 49), somadas à grande descentralização da política judiciária resultante do exercício do autogoverno pelos Tribunais, elas culminaram em um indesejável quadro de problemas nesse Poder, como denunciado por Machado (2008, p. 62):

Com o passar dos anos, o Poder Judiciário foi se desgastando em decorrência da morosidade, das faltas cometidas pelos magistrados e das ingerências administrativas cometidas pelos tribunais. Assim, o sistema do autogoverno se mostrou incapaz de atender aos reclamos sociais por um sistema judiciário célere, eficiente e seguro.

Para alguns pesquisadores, como Deocleciano (2010, p. 59), pode-se afirmar que o sistema de garantias previsto na Constituição Federal de 1988 resultou em uma verdadeira desordem institucional, constatando-se os seguintes pontos negativos no contexto do Poder Judiciário: a) acúmulo de demandas; b) morosidade processual; c) desrespeito aos princípios da Administração Pública (caso emblemático do nepotismo); d) desprestígio das ouvidorias; e) raridade das punições disciplinares e f) ausência de política centrada na gestão administrativa e financeira.

A solução de parte desses problemas que se acumulavam exigia a criação de novas formas de controle da atuação administrativa, financeira e disciplinar dos Tribunais, respeitada a preservação da imperiosa independência judicial decisional. Assim, a proposta de criação do Conselho Nacional de Justiça foi sendo fortificada, aceita e 
moldada gradativamente, passando a integrar um dos pilares da idealizada reforma do Poder Judiciário pátrio (MACHADO, 2008, p. 66).

Ao adotar essa postura, o Brasil alinha-se a outros países, tais como Itália, Grécia, França, Espanha e Portugal, cujos Conselhos de Justiça ou de magistratura já representavam uma sede de controle administrativo e disciplinar da magistratura sem qualquer ingerência na independência decisional (MORAES, 2008, p. 515), a revelar quão infundados eram os argumentos daqueles que se mostravam refratários à criação do CNJ. ${ }^{3}$

Assim, em 31 de dezembro de 2004, após intenso trâmite legislativo, foi publicada a Emenda Constitucional n. 45/2004; “a democratização do Poder Judiciário iniciou o processo de consolidação” (MACHADO, 2008, p. 66) a partir da criação do Conselho Nacional de Justiça (posteriormente instalado em 14 de junho de 2005). Indubitavelmente, o CNJ não nasceu como forma de controle externo ao exercício da atividade jurisdicional, compondo o rol de órgãos do Poder Judiciário, estabelecido no art. 92, inciso I-A da CF, sendo "órgão de cúpula administrativa do Poder Judiciário” (MORAES, 2008, p. 516).

Ademais, ainda que integrante do Judiciário, o CNJ não foi dotado de funções jurisdicionais, sendo composto por quinze membros, em sua maioria (nove) integrantes do próprio Poder - tendo, nos demais, representantes das funções essenciais à Justiça (advocacia e Ministério Público) e da sociedade, estes escolhidos pelo Legislativo (MORAES, 2008, p. 516). Mantém, portanto, a forte independência judicial institucional, tendo $60 \%$ de membros juízes e, dentre esses, o Presidente do Conselho e o Corregedor de Justiça (ROBL FILHO, 2012, p. 233). Todavia, como órgão interno, o CNJ igualmente sofre limitações impostas pela Constituição Federal e pela Lei Orgânica da Magistratura, e caso exceda suas funções ficará sujeito ao controle do Supremo Tribunal Federal (art. 102, inciso I, alínea “r”, CF), podendo até mesmo ser julgado pelo Senado Federal (art. 52, inciso II, CF) em caso de crime de responsabilidade (BRASIL, 1988b). Tais comandos demonstram que o CNJ na verdade não exerce um controle tão efetivo e externo, já que sua atuação fica sujeita, em última instância, ao crivo da Corte Constitucional.

A proeminência do Supremo tinha sido assegurada antes mesmo da efetiva instalação e funcionamento do CNJ. Com efeito, quando a constitucionalidade do CNJ foi questionada pela Associação dos Magistrados Brasileiros (AMB) através da Ação Direta de Inconstitucionalidade (ADIN) n. 3.367/DF, o Pleno do Supremo Tribunal Federal, por maioria, julgou improcedente referida ADIN, declarando constitucional a criação do Conselho Nacional de Justiça. Apesar de afastar os argumentos da AMB, entendendo que o novo órgão não afrontava a separação e independência dos poderes, limitou a atuação do CNJ aos órgãos jurisdicionais hierarquicamente inferiores ao STF e, complementarmente, confirmou-se o caráter nacional do CNJ como órgão administrativo do Poder Judiciário Nacional (STF, 2005). 
A partir do novo art. 103-B, $\S 4^{\circ}$, da Constituição Federal e do julgamento do STF sobre a ADIN n. 3.367/DF, sacramentou-se a competência do CNJ para exercer o controle da atuação administrativa e financeira do Poder Judiciário, bem como fiscalizar o cumprimento dos deveres funcionais dos juízes através das atribuições previstas no referido dispositivo constitucional.

Dentre as competências do CNJ será analisada apenas a função de coordenação da atividade administrativa dos Tribunais, realizada através do exercício do poder regulamentar, por se entender que tal atuação se mostra essencial para o desenvolvimento da política de transparência pública do Poder Judiciário, sobretudo quando são utilizadas Tecnologias de Informação e Comunicação (TIC's).

Conforme já salientado, a descentralização administrativa e do planejamento estratégico organizacional prejudicou o enfrentamento dos problemas que acometiam o Judiciário. Objetivando conciliar o autogoverno dos Tribunais com a natureza una e indivisível desse Poder, o Conselho Nacional de Justiça recebeu então uma função para além do mero "controle da atuação administrativa”, prevista constitucionalmente: teria a missão de executar a coordenação interna sobre os rumos administrativos do Judiciário de forma unitária, de maneira a conciliar sua autonomia e independência, com atuação administrativa condizente com os princípios previstos no artigo 37 da Constituição Federal, conforme explicado por Deocleciano (2010, p. 65):

Em nosso sentir, entendemos que mais apropriado seria falar em coordenação interna e não controle, porque o intuito não é, puramente, dominar ou mandar fazer no sentido de investir-se de maior poder e esgotar a autonomia dos Tribunais. Ao contrário, sua função é de propiciar maior autonomia ao Judiciário a partir de uma atividade coordenada, até porque, em sua maioria, é composto por membros das mais diversas instâncias. O controle apareceria como instrumento acessório, pertinente a possibilitar um ambiente de consenso e de respeito à própria dignidade da Justiça e não como um fim maior a ser perseguido pelo CNJ.

Essa coordenação interna da atividade administrativa dos órgãos do Poder Judiciário - exceto o Supremo Tribunal Federal - torna-se possível pela atividade regulamentadora do CNJ, prevista no art. 103-B, § 4 , I da CF. Fundamentada no Poder Normativo, tal atribuição consiste na capacidade de o Conselho expedir atos internos "regulando situações diretamente ligadas à sua própria organização, à administração judiciária, como também ao exercício dos deveres funcionais das carreiras ligadas, direta ou indiretamente, ao Judiciário, zelando pela sua autonomia” (DEOCLECIANO, 2010, p. 75).

Esse poder normativo, imprescindível para a condução de uma política una e nacional sobre os aspectos da atividade administrativa do Poder Judiciário - e que 
representa grande significado institucional - também suscitou contestações e polêmicas (MENDES, 2011, p. 1037), sobretudo quando se discutem seus limites de atuação.

Ao enfrentar o tema, Streck, Sarlet e Cléve (2005, p. 3-4) salientam que o constituinte derivado não delegou ao Conselho Nacional de Justiça o poder de vulnerar o princípio da reserva de lei e de jurisdição, de modo que suas Resoluções e demais atos regulamentares estariam submetidos a duas limitações: a) impossibilidade de expedição de regulamentos com caráter geral e abstrato, em face da reserva da lei; e b) impossibilidade de criar direitos e obrigação ou de ter ingerência nos direitos e garantias fundamentais dos cidadãos.

Na tentativa de dirimir a celeuma, o Supremo Tribunal Federal reconheceu a constitucionalidade da atuação regulamentar do Conselho, desde que exercido no âmbito das matérias previstas no $\S 4^{\circ}$ do art. 103-B da CF (MORAES, 2008, p. 522). O entendimento da Corte Suprema originou-se no julgamento da Ação Direta de Constitucionalidade n. 12 - ADC 12 -, proposta em face da Resolução CNJ n. $07 / 05$, conhecida como "resolução antinepotismo".

Conforme voto do Relator Ministro Carlos Ayres Britto, a constitucionalidade da Resolução então em apreço fundamenta-se: a) na presença dos atributos da generalidade (normas proibitivas de ações administrativas de logo padronizadas), impessoalidade (ausência de indicação nominal ou patronímica) e abstratividade; e b) no fato de sua temática derivar diretamente do art. 103-B da CF, tendo por finalidade densificar os princípios da legalidade, moralidade, eficiência e impessoalidade (previstos no art. 37 da CF) na atividade administrativa do Judiciário (STF, 2010).

Percebe-se uma divergência entre o entendimento do Relator, confirmado no término do julgamento em questão, e as lições de Streck, Sarlet e Cléve (2005, p. 3-4), notadamente em relação ao caráter de abstratividade e generalidade dos atos regulamentares do CNJ. Porém, como essa discussão é digna de um estudo específico que excede os limites deste trabalho, será adotado neste artigo o entendimento manifestado pelo STF.

Portanto, em conformidade com a interpretação da Corte, estando o dever de transparência pública consubstanciado no princípio da publicidade previsto no artigo 37 da $\mathrm{CF}$, torna-se plenamente viável o exercício do poder normativo primário pelo CNJ nesse tema. O exercício da atividade regulamentadora nesse norte é de relevância ímpar, porquanto a temática da transparência pública e da ampla divulgação das informações que estão sob o poder da Administração Pública à sociedade é a pedra angular do controle social sobre a atividade estatal, conforme abordado na primeira parte deste artigo.

No âmbito do Judiciário, tal importância é reforçada na medida em que tal Poder, a despeito de seu papel na defesa das garantias individuais e sociais no Estado Democrático de Direito, sempre esteve muito distante da população, em parte porque seus agentes não são elegíveis, mas também pela cultura hermética e fechada que conduzia sua Administração (OLIVEIRA, 2010, p. 129). 
Uma vez delineada a competência do CNJ atinente à matéria, no próximo tópico será evidenciada a atuação regulamentar desse órgão para impulsionar a transparência pública, sobretudo pela disponibilização de informações nos portais e sites dos tribunais, medida que se revela fundamental para a democratização do Poder Judiciário.

\subsection{O EXERCÍCIO DO PODER NORMATIVO PRIMÁRIO PELO}

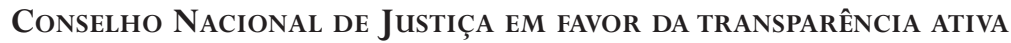

Para cumprir o objetivo principal da pesquisa ora apresentada, foram analisadas todas as Resoluções exaradas pelo Conselho Nacional de Justiça no exercício do seu poder normativo, desde sua respectiva previsão constitucional, pela publicação e vigência da Emenda Constitucional n. 45/2004, até o dia 25 de julho de 2013.

Nesse exame, conduzido pela técnica de pesquisa documental, objetivou-se selecionar as regulamentações que contivessem obrigações direcionadas aos órgãos sujeitos à atuação do CNJ destinadas a promover a transparência pública no âmbito de suas atuações administrativa e financeira, valendo-se especialmente da Internet. Com isso buscou-se investigar tanto a transparência ativa do Poder, consubstanciada na divulgação espontânea de informações públicas de interesse coletivo, quanto examinar a transparência passiva, ou seja, o atendimento das demandas apresentadas pelo cidadão.

Os resultados desse estudo foram delineados na tabela que acompanha o presente artigo científico (Tabela de Resoluções do Conselho Nacional de Justiça selecionadas pela pesquisa documental), dividida em quatro colunas: a) identificação do ato regulamentar; b) dispositivos que regulamentam deveres de transparência ativa e passiva, com identificação de sua função; c) obrigações impostas aos órgãos do Poder Judiciário; e d) previsão da mesma obrigação pela Lei n. 12.527/11 - Lei de Acesso à Informação Pública.

Foram constatadas cinco Resoluções que, atendendo aos critérios preestabelecidos na pesquisa documental, impõem aos órgãos submetidos à atuação do CNJ a obrigação de divulgar informações relativas à gestão administrativa e financeira por meio dos sítios eletrônicos mantidos na rede mundial de computadores: Resoluções n. 76, 79, 83, 102, 115 .

Entre elas, apenas as Resoluções n. 79 e 102, de 09 de junho de 2009 e 15 de dezembro de 2009, respectivamente, possuem como tema central a regulamentação do dever de publicidade das informações alusivas à gestão orçamentária e financeira, aos quadros de pessoal e respectivas estruturas remuneratórias dos tribunais e conselhos. São, indubitavelmente, os grandes marcos da atuação normativa do CNJ nessa área, a partir dos quais se constata sua preocupação em relação à necessária transparência ativa referente à gestão financeira dos órgãos do Poder Judiciário.

A Resolução n. 79, em seu art. $3^{\circ}$, obrigou os Tribunais e Conselhos a criarem, em seus sítios eletrônicos, um campo de informações denominado "transparência”, onde 
disponibilizariam os dados concernentes à programação e execução orçamentária, contendo, no mínimo:

a) informações pormenorizadas sobre a execução orçamentária e financeira, com discriminação dos valores desembolsados, mensal e anualmente, e classificação de todas as despesas por rubrica própria e específica, a título de pessoal, investimentos ou custeio, vedada a identificação genérica de pagamentos ("pessoal”, "vantagens”, "outros" ou "diversos", por exemplo);

b) no pagamento a fornecedores, os dados referentes ao número do correspondente processo, ao bem fornecido ou ao serviço prestado, à pessoa natural ou jurídica beneficiária do pagamento e, quando for o caso, ao procedimento licitatório realizado;

c) o lançamento e o recebimento de toda receita destinada às unidades gestoras, inclusive referentes a recursos extraordinários. (BRASIL, 2009d)

Posteriormente o CNJ complementou a Resolução n. 79 através da Resolução n. 102, ocasião em que detalhou as informações que deveriam ser publicadas no item "transparência” dos sítios eletrônicos dos órgãos. A partir dessa normativa ampliou-se o dever de divulgação para áreas diversas da gestão financeira: organização funcional e remuneração dos ocupantes de cargos; divulgação do quadro de magistrados e demais agentes públicos; relação dos empregados de empresas contratadas em exercício nos órgãos e relação dos servidores e/ ou empregados não integrantes do quadro próprio em exercício no órgão, dentre outras previsões (BRASIL, 2009f).

Ademais, acertou o CNJ ao exigir, na Resolução n. 102, que a publicidade dessas informações ocorresse de acordo com seus artigos $2^{\circ}$ e $3^{\circ}$, mediante itens temáticos específicos - detalhamento esse que contribui para maior qualidade do controle ulterior, social ou horizontal. Essa Resolução também contemplou anexos com a finalidade de uniformizar a divulgação de informações em todos os tribunais e conselhos, o que além de beneficiar o estudo e acompanhamento estatístico das gestões igualmente permite um controle ulterior de maior qualidade (BRASIL, 2009f).

Outra determinação que evidencia a atenção do CNJ à evolução das Tecnologias de Informação e Comunicação (TIC's) é a contida no $§ 3^{\circ}$ do artigo $4^{\circ}$ dessa Resolução, obrigando a publicação das informações em formato hipertexto (HTML - Hypertext Markup Language), cuja cópia deverá estar disponível em arquivo para download no sítio dos órgãos (BRASIL, 2009f). Essa determinação expressa a atenção que todos os órgãos públicos devem ter com a população, produzindo conteúdos que possam ser facilmente acessados e armazenados pelos cidadãos.

As demais Resoluções, por outro lado, referem-se a temáticas diversas, cons- 
tantes na primeira coluna da Tabela. O ponto em comum refere-se ao fato de que contemplam dispositivo específico no qual há previsão de dever de ampla divulgação de informações nos sítios eletrônicos mantidos na internet. Dentre elas, cumpre salientar a importância ímpar da Resolução n. 76, que criou o Sistema de Estatísticas do Poder Judiciário (SIESPJ) e obrigou os Tribunais a manterem em seus portais oficiais um espaço permanente para divulgação dos dados estatísticos relativos à atuação administrativa e jurisdicional, explicitando inclusive a produtividade dos magistrados (BRASIL, 2009c).

Nota-se, portanto, que o CNJ diversificou sua atenção normativa, regulamentando não apenas a publicidade de informações oriundas da gestão financeira e orçamentária, mas também a atuação administrativa e jurisdicional, o que possibilita maior controle social sobre a eficiência do Poder Judiciário e integrantes da magistratura. Trata-se, então, de um importante mecanismo de prevenção à morosidade, porquanto conduz à exposição pública os focos de ineficiência existentes na magistratura nacional. Além disso, a divulgação dessas estatísticas permite a elaboração de pesquisas científicas que poderão contribuir para a realização do planejamento estratégico dos órgãos - o que seria uma manifestação louvável de democratização na Administração Pública. Salientase que todas essas Resoluções selecionadas e constantes da tabela anexada preconizam obrigações que se situam no ambiente da transparência pública ativa.

Por outro lado, entende-se que a transparência passiva, segundo a qual os órgãos públicos atendem as demandas dos cidadãos, não foi abordada satisfatoriamente pelo CNJ no exercício de seu poder normativo. A Resolução n. 79, através do seu artigo $3^{\circ}$, estabelece a obrigação dos Tribunais manterem serviço de atendimento aos usuários da Justiça, preferencialmente por ouvidorias (BRASIL, 2009d). Porém, além de não ter ampliado tal dever aos sítios eletrônicos, não obrigados a manter atendimento on-line, o dispositivo preconiza que esse serviço seria destinado apenas a "receber sugestões, críticas e reclamações acerca de suas atividades administrativas e jurisdicionais", o que não contempla o recebimento e processamento de pedidos de informação. Essa lacuna é preocupante, uma vez que não se coaduna com a postura democrática que se impõe ao Poder Judiciário.

Digno de destaque o fato de todas as Resoluções constantes da Tabela terem sido publicadas em período anterior ao advento da Lei n. 12.527/11 - Lei de Acesso à Informação (LAI) . Na esteira do que foi afirmado na primeira parte deste artigo, a LAI positivou obrigações de transparência ativa e passiva a uma grande gama de entidades e órgãos públicos, dentre os quais os integrantes do Poder Judiciário. Inegavelmente sua publicação foi tardia, principalmente se comparada à atuação de outros países cujo direito à informação já estava regulamentado. A regulamentação tardia conferiu ainda maior relevância à atuação normativa do CNJ, que desde o ano de 2009 cumpre o dever de transparência pública.

Em que pese o fato de que uma primeira leitura possa conduzir à interpretação 
de que o CNJ tenha se antecipado aos comandos da Lei n. 11.527/2011, mesmo assim sua atuação normativa deixa a desejar, já que desde sua criação poderia, a exemplo da atuação do Poder Executivo federal, observar o dever de transparência pública ativa e disponibilizar no Portal da Transparência informações referentes a recursos públicos federais (BRASIL, 2004m).

Não se pode olvidar também que a análise comparativa entre as obrigações contidas nas Resoluções selecionadas e nas normas contidas na LAI demonstrou que a atuação regulamentar do CNJ ocorreu em pontos diversos, notadamente em relação à publicação de informações decorrentes da gestão de precatórios (Resolução n. 115) e dos relatórios estatísticos da atuação administrativa e jurisdicional (Resolução n. 76). No que tange à transparência ativa das informações originadas na gestão orçamentária, financeira e de recursos humanos, a Resolução n. 102 é mais abrangente, detalhada e exigente do que a novel legislação, evidenciando sua importância para a política de transparência atualmente executada no âmbito do Poder Judiciário.

Por fim, destaca-se que como o campo de incidência da LAI é extremamente amplo, atingindo um grande número de entidades da Administração Pública Direita e Indireta (além de entidades privadas), a maioria das obrigações que impõe são genéricas, com um grande número de normas principiológicas. Esse caráter torna fundamental a atuação regulamentar dos órgãos administrativos competentes (no caso específico do Judiciário, o CNJ) para normatização da publicação ativa de informações relacionadas a temas próprios e específicos de sua atividade.

Será importante, então, que o CNJ, a quem incumbe à coordenação da política administrativa do Poder Judiciário, publique um ato normativo específico para regulamentar a aplicação da Lei n. 12.527/11 nesse Poder, dispondo, dentro dos limites legais (reserva da lei), sobre as principais adaptações que os Tribunais terão de realizar em sua gestão para respeitar integralmente os dispositivos nela positivados, tais como: procedimentos internos tendentes ao cumprimento dos deveres de transparência passiva; estruturação obrigatória de órgãos e divisões administrativas para gestão das informações produzidas e custodiadas; forma unificada de divulgação das informações nos sítios mantidos na rede mundial de computadores; detalhamento maior das informações que deverão ser publicadas ativamente e controle de informações sigilosas. As resoluções selecionadas na pesquisa documental são um avanço, mas insuficientes para a complexidade do direito fundamental de acesso à informação regulamentado pela Lei n. 12.527/11.

Indubitavelmente, tal ação regulamentar já deveria ter ocorrido em virtude de sua importância para a consolidação de um sistema de transparência pública uniforme em todos os órgãos do Poder Judiciário. A condução da gestão administrativa desse modo foi um dos pressupostos da criação do Conselho Nacional de Justiça, consistindo em função de grande relevância, que deve sempre ser executada de forma célere e técnica, a fim de proporcionar uma atividade pública coadunada com 
os princípios do artigo 37 da Constituição Federal.

\section{CONSIDERAÇÕES FINAIS}

Através do aporte teórico, construído a partir da pesquisa bibliográfica e documental sobre o tema, inicialmente verificou-se a evolução do dever de transparência na sociedade informacional, com destaque para alguns documentos internacionais. Por meio desse estudo, percebeu-se a importância da utilização das Tecnologias de Informação e Comunicação (TIC's), especialmente a Internet, para o cumprimento do dever de transparência ao proporcionar o acesso à informação e exercício da ciberdemocracia na sociedade informacional.

Em um segundo momento, foram abordados aspectos históricos relacionados à criação e ao reconhecimento do Conselho Nacional de Justiça (CNJ) como órgão responsável pela coordenação da política administrativa do Poder Judiciário, bem como a premissa de que a concretização dessa função depende diretamente do exercício do seu poder normativo regulamentar perante os órgãos sujeitos a sua atuação.

De posse dessas premissas, buscou-se neste estudo verificar as iniciativas normativas do Conselho Nacional de Justiça que direcionassem obrigações de transparência ativa e passiva aos órgãos integrantes do Judiciário sobre sua atuação administrativa e financeira, aproveitando-se as potencialidades de publicidade geradas na Internet. A pesquisa documental teve como marco inicial a criação do CNJ e como marco final o dia 25 de julho de 2013, abrangendo período temporal pretérito e posterior à regulamentação do direito fundamental à informação pela Lei n. 12.527.

Constatou-se que desde 2009 o Conselho Nacional de Justiça exerce sua competência normativa no norte pesquisado, tendo sido selecionadas as Resoluções n. 76, 79, 83, 102 e 115. Todas elas estabelecem o dever de transparência ativa (publicação da informação, independentemente de requerimento prévio) aos órgãos do Poder Judiciário, através dos sítios eletrônicos mantidos na rede mundial de computadores.

A Resolução n. 102, especificamente, simboliza a atenção que o Conselho conferiu à publicidade das informações resultantes da gestão financeira e execução orçamentária, com ampla divulgação das mesmas na Internet, apresentando-se como uma referência de qualidade para a atuação futura do órgão no tema da transparência pública, em razão do seu detalhamento e do rigor técnico empregado.

Contudo, essas mesmas características positivas não foram encontradas no que tange à disciplina de obrigações de transparência pública passiva. Essa, apesar de possuir relevância inquestionável no âmbito do Estado Democrático de Direito, não recebeu a devida atenção pelo CNJ, uma vez que a criação de ouvidorias não pode ser considerada a única medida suficiente para atender as solicitações decorrentes do exercício do direito fundamental de acesso à informação. Assim, o potencial a ser explorado nessa área pelo poder normativo do CNJ é amplo, abrangendo desde a fixação das estruturas 
administrativas obrigatórias para o cumprimento eficaz do dever, passando pela incumbência de regulamentação de diretrizes para o armazenamento, até a gestão digital das informações públicas produzidas.

Outra lacuna ainda existente (cuja solução deve ser prioritária e urgente) diz respeito à adoção de mecanismos para o cumprimento da Lei n. 12.527/11 no âmbito do Poder Judiciário. Esse marco legal, de relevância ímpar para a eficácia do direito fundamental de acesso às informações públicas, é complexo e exige atuação normativa do CNJ, tanto no sentido de adequar as obrigações legais à realidade particular do Poder (com a publicação espontânea de informações) quanto para preconizar uma política administrativa uniforme, pautada no paradigma da máxima divulgação.

Nesse sentido, tem-se que a atuação do CNJ na temática pesquisada é positiva em alguns aspectos, mas necessita de melhor atuação regulamentar futura em outros. A condução da política judiciária nacional pelo Conselho, mediante o exercício do seu poder normativo, não pode desconsiderar a extrema relevância do direito fundamental de acesso às informações públicas, principalmente no contexto atual da sociedade informacional.

O Poder Judiciário, enquanto responsável pela tutela dos direitos e garantias fundamentais e, consequentemente, um símbolo do Estado Democrático de Direito, deveria, inclusive, ser referência de qualidade e eficiência no cumprimento do dever de

: ARTIGO APROVADO (02/12/2013) : RECEBIDO EM 30/07/2013

NOTAS

* O presente artigo representa os resultados parciais do Projeto de Pesquisa "O uso das tecnologias da informação e comunicação pelo Poder Judiciário brasileiro: os sites e portais como instrumentos para implementar a Lei $\mathrm{n}$. 12.527/11", desenvolvido no Curso de Direito da Universidade Federal de Santa Maria, contemplado com recursos do Edital n. 18/2012 do CNPq.

1 Em nível mundial o reconhecimento do direito de acesso à informação, erigido à categoria de direito humano fundamental, passou a ser objeto de debates e de realização de compromissos internacionais a partir do período pós-guerra, dentre os quais se destacam: a Declaração Universal dos Direitos Humanos (ONU, 1948), elaborada em 10 de dezembro de 1948; o Pacto Internacional sobre Direitos Civis e Políticos, firmado em 1966, aprovado no Congresso Nacional pelo Decreto Legislativo n. 226, de 12 de dezembro de 1991, ao que se seguiu a expedição do Decreto Presidencial n. 592, de 06 de julho de 1992 (BRASIL, 1992k); a Convenção Interamericana de Direitos Humanos, conhecida como Pacto de San José da Costa Rica, firmado em 22 de novembro de 1969 (COMISSÃO, 2000) e internalizado no Brasil por meio do Decreto Presidencial n. 678, de 06 de novembro de 1992 (BRASIL, 1992i); a Convenção das Nações Unidas Contra a Corrupção, aprovada pela Assembleia Geral das Nações Unidas em outubro de 2003 (ONU, 2003), apro- 
vada pelo Congresso Nacional por meio do Decreto Legislativo n. 348, de 18 de maio de 2005 (BRASIL, 2005h) e promulgada pelo Decreto Presidencial n. 5.687, de 31 de janeiro de 2006 (BRASIL, 2006j).

2 O direito à informação foi erigido à categoria de direito fundamental pela Assembleia Constituinte no artigo $5^{\circ}$, inciso XXXIII: “Todos têm direito a receber dos órgãos públicos informações de seu interesse particular, ou de interesse coletivo ou geral, que serão prestadas no prazo da lei, sob pena de responsabilidade, ressalvadas aquelas cujo sigilo seja imprescindível à segurança da sociedade e do Estado” (BRASIL, 1988b).

3 Aliás, conforme explica Mendes (2011, p. 1033), nesses países europeus, em que algumas atribuições de governo e administração dos tribunais, como seleção, nomeação e fiscalização de magistrados eram normalmente atribuídas a um órgão do Poder Executivo, os Conselhos de Magistratura foram criados com o objetivo principal de limitar a atuação do Executivo, na medida em que tais competências eram utilizadas como forma de interferência no Judiciário.

\section{REFERÊNCIAS BIBLIOGRÁFICAS}

ARTIGO 19. O direito do público a estar informado. Princípios sobre a legislação de liberdade de informação. Artigo 19: Londres, 1999. Disponível em: <http://www.article19.org/data/files/pdfs/standards/public-rightto-know-portuguese.pdf>. Acesso em: 20 jul. 2013.

BRASIL. Comitê Gestor da Internet no Brasil. Neutralidade na Rede: Internet para todos. Revista .br, Ano 03, edição 04, 2011a.

Constituição da República Federativa do Brasil de 1988b. Brasília: Senado Federal, 1988. Disponível em: <http://www.planalto.gov.br/ccivil_03/constituicao/constitui\%C3\%A7ao.htm>. Acesso em: 23 jul. 2013. . Conselho Nacional de Justiça. Resolução n. 76c. Dispõe sobre os princípios do Sistema de Estatística do

Poder Judiciário, estabelece seus indicadores, fixa prazos, determina penalidades e dá outras providências. Disponível em: <http://www.cnj.jus.br/atos-administrativos/atos-da-presidencia/resolucoespresidencia?start=100>. Acesso em: 25 jul. 2013.

Resolução n. 79d. Dispõe sobre a transparência na divulgação das atividades do Poder Judiciário brasileiro e dá outras providências. Disponível em: <http://www.cnj.jus.br/atos-administrativos/atos-da-presidencia/323-resolucoes/12197-resolucao-no-79-de-9-de-junho-de-2009 >. Acesso em: 25 jul. 2013. Resolução n. 83e. Dispõe sobre a aquisição, locação e uso de veículos no âmbito do Poder Judiciário brasileiro e dá outras providências. Disponível em: <http://www.cnj.jus.br/atos-administrativos/atosda-presidencia/resolucoespresidencia?start=90> . Acesso em: 25 jul. 2013.

. Resolução n. 102f. Dispõe sobre a regulamentação da publicação de informações alusivas à gestão orçamentária e financeira, aos quadros de pessoal e respectivas estruturas remuneratórias dos tribunais e conselhos. Disponível em: <http://www.cnj.jus.br/atos-administrativos/atos-da-presidencia/resolucoespresidencia/12218resolucao-no-102-de-15-de-dezembro-de-2009>. Acesso em: 25 jul. 2013.

Resolução n. 115g. Dispõe sobre a Gestão de Precatórios no âmbito do Poder Judiciário. Disponível em: <http://www.cnj.jus.br/atos-administrativos/atos-da-presidencia/resolucoespresidencia?start=60>. Acesso em: 25 jul. 2013.

Decreto Legislativo n. 348, de 18 de maio de 2005h. Aprova o texto da Convenção das Nações Unidas contra a Corrupção, adotada pela Assembleia-Geral da Organização das Nações Unidas em outubro de 2003. Disponível em: <http://www.cgu.gov.br/onu/convencao/arquivo/Dec_Legislativo_Convencao.pdf>. Acesso em: 23 jul. 2013.

Decreto n. 678, de 06 de novembro de 1992i. Promulga a Convenção Americana sobre Direitos Humanos (Pacto de São José da Costa Rica), de 22 de novembro de 1969. Disponível em: <http://www.planalto.gov.br/ ccivil_03/decreto/D0678.htm>. Acesso em: 23 jul. 2013.

. Decreto Presidencial n. 5.687, de 31 de janeiro de 2006j. Promulga a Convenção das Nações Unidas contra a Corrupção, adotada pela Assembleia-Geral das Nações Unidas em 31 de outubro de 2003 e assinada pelo Brasil em 9 de dezembro de 2003. Disponível em: <http://www.planalto.gov.br/ccivil_03/_Ato20042006/2006/Decreto/D5687.htm>. Acesso em: 23 jul. 2013.

. Decreto Presidencial n. 592, de 06 de julho de 1992k. Atos Internacionais. Pacto Internacional sobre Direitos Civis e Políticos. Promulgação. Disponível em: < http://www.planalto.gov.br/ccivil_03/decreto/19901994/D0592.htm>. Acesso em: 23 jul. 2013. 
Lei n. 12.527, de 18 de novembro de 2011. Regula o acesso a informações previsto no inciso XXXIII do art. $5^{\circ}$, n. inciso II do $\S 3^{\circ}$ do art. 37 e no $\S 2^{\circ}$ do art. 216 da Constituição Federal; altera a Lei no 8.112, de 11 de dezembro de 1990; revoga a Lei no 11.111, de 5 de maio de 2005, e dispositivos da Lei n. 8.159, de 8 de janeiro de 1991; e dá outras providências. In: Diário Oficial da República Federativa do Brasil, Brasília, 18 out. 2011. Disponível em: <http://www.planalto.gov.br/ccivil_03/_ato2011-2014/2011/lei/112527.htm>. Acesso em: 20 jul. 20131.

Portal da Transparência do Governo Federal. Disponível em: <http://www.portaltransparencia.gov.br/>. Acesso em: 23 jul. 2013.

Supremo Tribunal Federal. ADI n. 3367n. Relator Ministro Cezar Peluso. 13 de abril de 2005, Pleno: Diário de Justiça, Brasília, DF, 22 set. 2006.

ADC n. 12-MCo. Relator Ministro Carlos Britto. 16 de fevereiro de 2006. Diário de Justiça,

Brasília, DF, 01 set. 2006.

CASTELLS, Manuel. A sociedade em rede - a era da informação: economia, sociedade e cultura. 5.ed. Traduzido por Klauss Brandini Gerhardt e Roneide Vanancio Majer. São Paulo: Paz e Terra, 1999.

. A Galáxia da Internet: reflexões sobre a Internet, os negócios e a sociedade. Traduzido por Maria

Luiza X. De A. Borges, revisão Paulo Vaz. Rio de Janeiro: Zahar, 2003.

COMISSÃO INTERAMERICANA DE DIREITOS HUMANOS. Declaração de Princípios sobre Liberdade de expressão. Aprovado pela Comissão Interamericana de Direitos Humanos em seu $108^{\circ}$ período ordinário de sessões, celebrado de 16 a 27 de outubro de 2000. Disponível em: <http://www.cidh.oas.org/basicos/portugues/ s. Convencao.Libertade.de.Expressao.htm>. Acesso em: 23 jul. 2013.

DEOCLECIANO, Pedro Rafael Malveira. O Conselho Nacional de Justiça e o controle democrático do Poder Judiciário: uma realidade possível?. Disponível em: <http://uol02.unifor.br/oul/ObraBdtdSiteTrazer.do?method= trazer\&obraCodigo $=85815$ \&programaCodigo $=84 \& \mathrm{~ns}=$ true $>$. Acesso em: 20 jul .2013.

FERNANDES, Bernardo Gonçalves. Curso de Direito Constitucional. Rio de Janeiro: Lumen Juris, 2011.

INTERNACIONAL CONFERENCE ON THE RIGHT PUBLIC INFORMATION. February, 27-29, 2008.

Declaração de Atlanta e plano de ação para o avanço do direito de acesso à informação. Disponível em:

<http://www.cartercenter.org/resources/pdfs/peace/americas/atlanta_declaration_unofficial_portuguese.pdf > . Acesso em: 23 jul. 2013.

LEVY, Pierre. Cibercultura. São Paulo: Editora 34, 1999.

MACHADO, Natália Gaspar. O Conselho Nacional de Justiça: um estudo da função normativa. Disponível em: <http://www6.univali.br/tede/tde_busca/arquivo.php?codArquivo=565>. Acesso em: 20 jul. 2013.

MARTINS, Paula Lígia. Acesso à informação: um direito fundamental e instrumental. Acervo: Rio de Janeiro, 2011. MENDES, Gilmar Ferreira; BRANCO, Paulo Gustavo Gonet Branco. Curso de Direito Constitucional. 6.ed. São Paulo: Saraiva, 2011.

MIRAGEM, Bruno. A Nova Administração Pública e o Direito Administrativo. São Paulo: Revista dos Tribunais, 2011. MORAES, Alexandre de. Direito Constitucional. 23.ed. São Paulo: Atlas, 2008.

OLIVEIRA, Vitor Costa. O Conselho Nacional de Justiça e a cultura política brasileira. Disponível em:

<http://bdtd.ufs.br/tde_busca/arquivo.php?codArquivo=540>. Acesso em: 21 jul. 2013.

ORGANIZAÇÃO DAS NAÇÕES UNIDAS. Convenção das Nações Unidas Contra a Corrupção. Disponível em: <http://www.unodc.org/pdf/brazil/ConvONUcorrup_port.pdf>. Acesso em: 23 jul. 2013.

. Declaração Universal dos Direitos Humanos. Adotada e proclamada pela resolução 217 A (III) da

Assembléia Geral das Nações Unidas em 10 de dezembro de 1948. Disponível em: <http://portal.mj.gov.br/ sedh/ct/legis_intern/ddh_bib_inter_universal.htm>. Acesso em: 23 jul. 2013.

. Pacto Internacional sobre Direitos Civis e Políticos, 1966. Disponível em: <http://portal.mj.gov.br/ sedh/ct/legis_intern/pacto_dir_politicos.htm>. Acesso em: 23 jul. 2013.

PIANA, Ricardo Sebastián. Gobierno elecrónico: gobierno, tecnologias y reformas. La Plata: Univ. Nacional de La Plata, 2007.

ROBL FILHO, Ilton Norberto. Conselho Nacional de Justiça: Estado Democrático de Direito e Accountability. São Paulo: Saraiva, 2012.

STRECK, Lenio Luiz; SARLET, Ingo Wolfgang; CLÉVE, Clemerson Merlin. Os limites constitucionais das resoluções do Conselho Nacional de Justiça (CNJ) e Conselho Nacional do Ministério Público (CNMP). Disponível em: $<$ http://www.egov.ufsc.br/portal/conteudo/os-limites-constitucionais-das-resolu\%C3\%A7\%C3\%B5es-do-conselho-nacional-de-justi\%C3\%A7a-cnj-e-conselho-na>. Acesso em: 24 jul. 2013. 
ANEXO:

Tabela de Resoluções do Conselho Nacional

DE JUSTIÇA SELECIONADAS PELA PESQUISA DOCUMENTAL

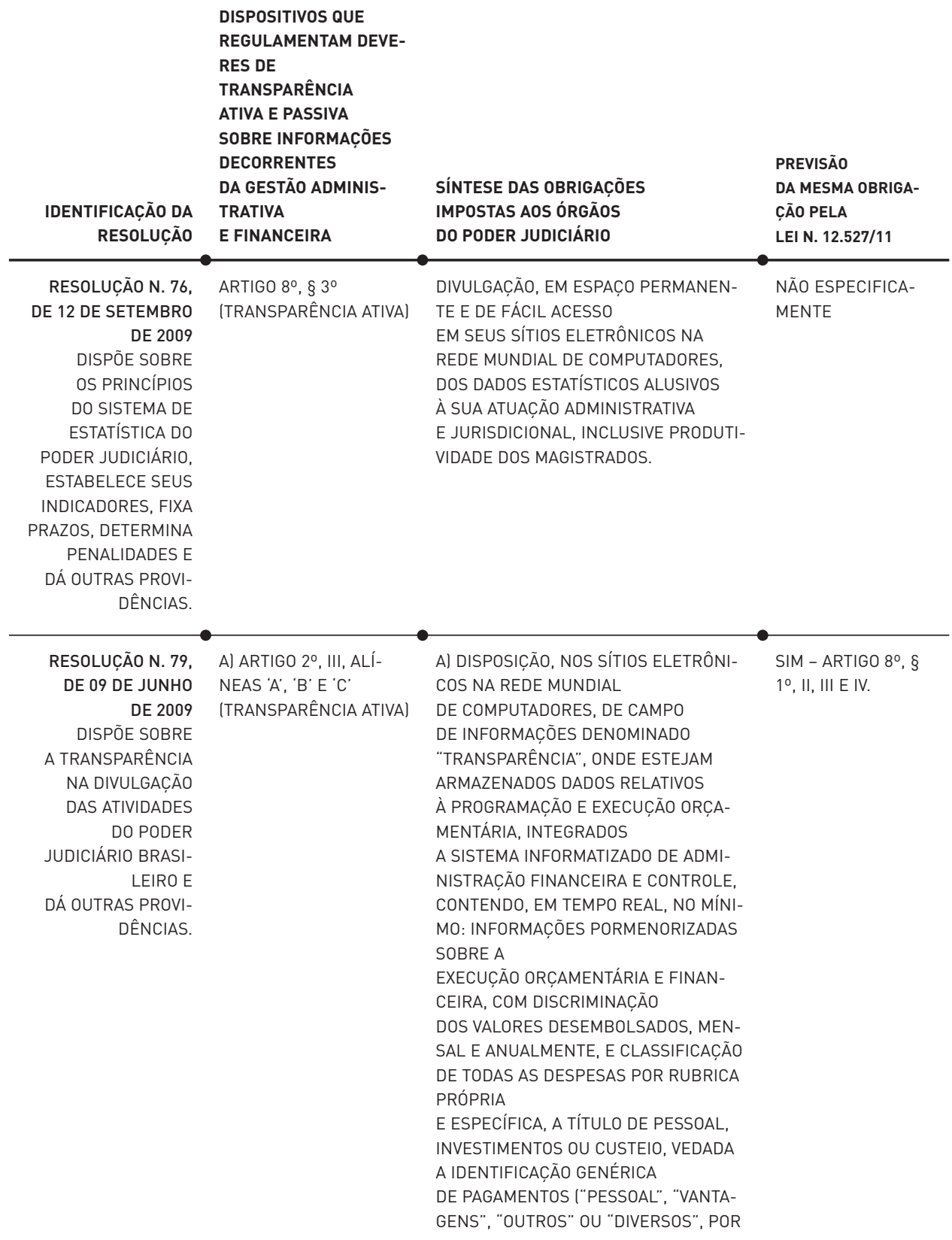




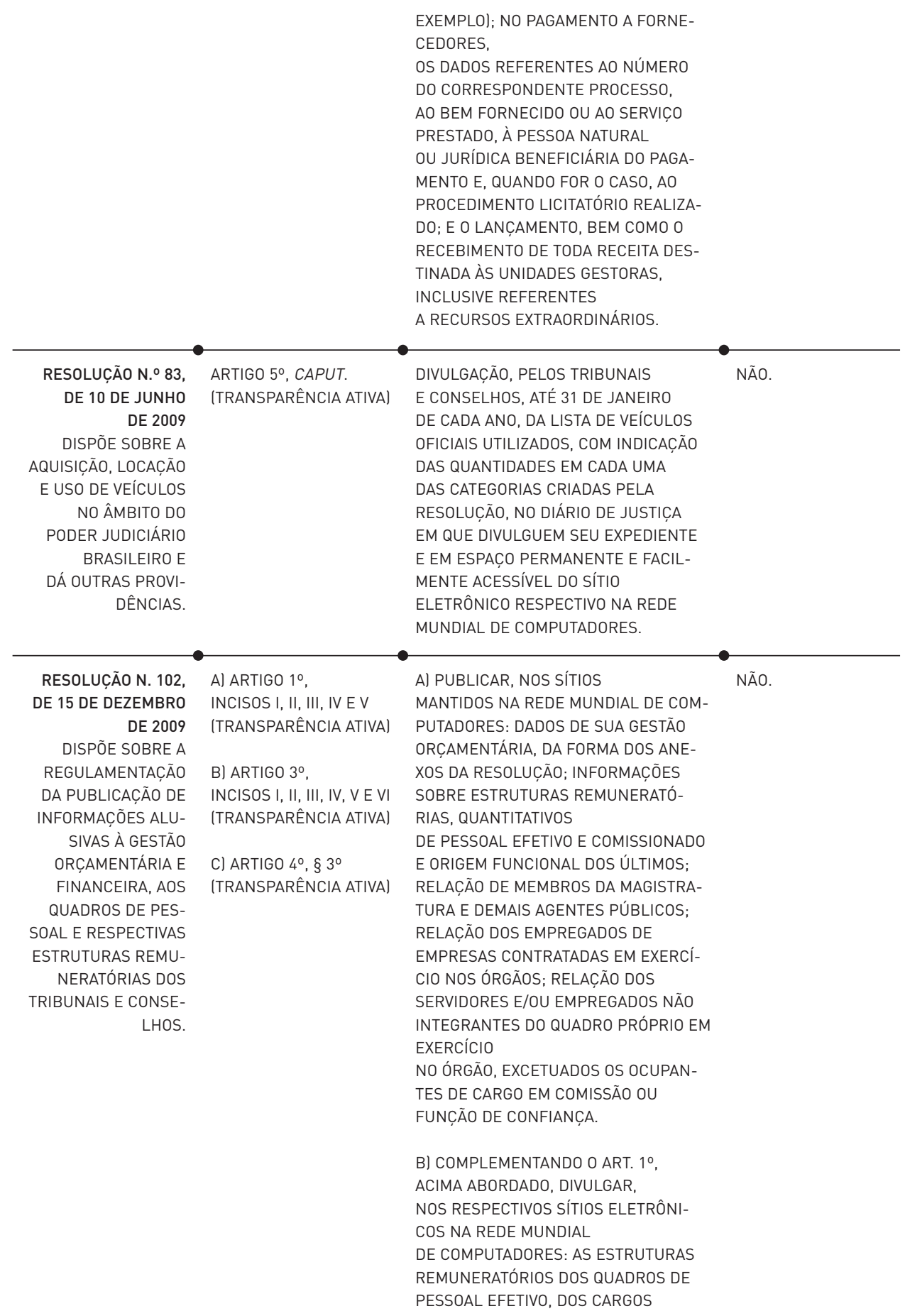




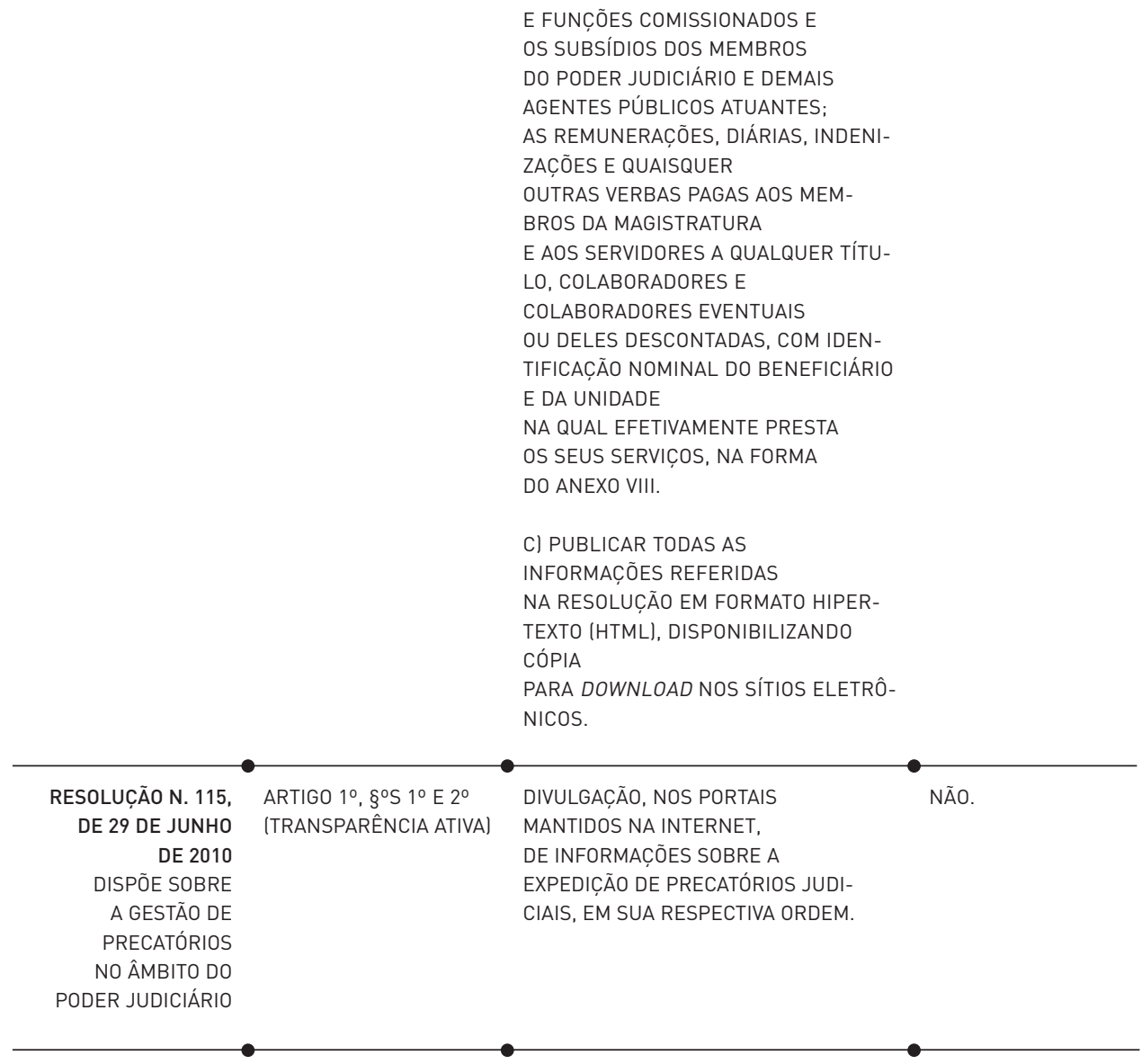

Fontes:

Resoluções do Conselho Nacional de Justiça. Disponíveis em: < http://www.cnj.jus.br/atos-administrativos/atos-da-presidencia/resolucoespresidencia>. Acesso em: 25 jul. 2013.

Lei n. 12.527, de 18 de novembro de 2011. Regula o acesso a informações previsto no inciso XXXIII do art. $5^{\circ}$, no inciso II do $\S 3^{\circ}$ do art. 37 e no $\S 2^{\circ}$ do art. 216 da Constituição

Federal; altera a Lei n. 8.112, de 11 de dezembro de 1990; revoga a Lei n. 11.111, de 5 de maio de 2005, e dispositivos da Lei n. 8.159, de 8 de janeiro de 1991; e dá outras providências.

In: Diário Oficial da República Federativa do Brasil, Brasília, 18 out. 2011. Disponível em: <http://www.planalto.gov.br/ccivil_03/_ato2011-2014/2011/lei/l12527.htm>. Acesso em: 20 jul. 20131. 
Rua Appel, n. 64, ap. 602 Centro - 97015-030 Santa Maria - RS - Brasil rosaneleals@terra.com.br

Rua Coronel Valença, n. 21 Passo da Areia - 97020-180

Santa Maria - RS - Brasil patricia.adrianilahotmail.com

Rua São Vicente Pallotti, n. 32 Patronato - 97020-680 Santa Maria - RS - Brasil lucasarsflorescoelhoerighi.adv.br

\section{Rosane Leal da Silva}

CoOrdenadora do Núcleo de DiReito InFormacional da Universidade Federal de Santa Maria

Professora do Centro Universitário Franciscano

Professora Adjunta do Curso de Direito DA Universidade FEDERAL de SANTA MARIA, COM ATUAÇÃOO NA GRADUAÇÃO E MESTRADO

DOUTORA EM DIREITO PELA Universidade FEDERAL de SANTA CATARINA

\section{Patrícia Adriani Hoch}

ACADÊMICA dO CURSO dE DIREITO DA Universidade Federal de SANTA Maria INTEGRANTE DO NúCLEO DE DIREITO INFORMACIONAL da Universidade Federal de Santa Maria

\section{Lucas Martins Righi}

Pós-Graduado em Direito Tributário E EMPRESARIAL PELA UNIVERSIDADE ANHANGUERA GRADUAdo EM DiREITO PELA Universidade FEDERAL dE SANTA Maria INTEGRANTE DO NúCLEO DE DIREITO INFORMACIONAL da Universidade FEderal de Santa Maria 
